\title{
Consultor Jurídico do D.A.S.P.
}

Criação de Parques Nacionais. Competencia do Presidente da Re pública através de decreto.

\section{PARECER}

\section{I}

Consulta a Divisão de Orçamento e Organização dêste Departamento (D.O.) sôbre a legalidade da criação de Parque Nacional através de decreto do Poder Executivo.

2. Trata-se do Parque Nacional do Araguaia, que seria localizado, como se esclarece, na totalidade da Ilha do Bananal, no Estado de Goiás, área essa doada à Uniấo para êsse fim, forma da Lei Estadual n. ${ }^{0} 2.370$, de 17 de dezembro de 1958.

3. A dúvida da D.O. prende-se ao fato de não haver uniformidade quanto a criaçōes de Parques dessa natureza, ora promovidas por ato do Poder Executivo, ora por decretosleis, de que são exemplos os de ns. ${ }^{\circ} 337$, de 16 de março de 1938; 1.035 , de 10 de janeiro de 1939, e 1.822, de 30 de novembro de 1939.

4. Daí a indagação formulada pela Divisão consulente, sôbre a qual passo a emitir o meu parečer.

\section{II}

5. A criação em si de Parques Nacionais em áreas do dominio da União não é matéria de competência formalmente legislativa, em ${ }^{2}$ bora dai se não infira, como é evidente, que seja defesa a lei dispor sôbre tal destinação.

6. E claro que ato legislativo poderá estabelecer sôbre a criação dêsses Parques, mas, em sua essência, a matéria é formalmente administrativa. Em outras palavras, o Poder Executivo tem competência para destinar áreas de propriedade da União à constituição de Parques Nacionais.

7. A perplexidade da D.O., em face da existência de atos formalmente legislativos e administrativos quanto à criação de tais Parques, tem explicação no fato de que os atos legislativos, que cita e que se acham indicados no item 3 dêste parecer, se constituiam em decretos-leis, quando, no regimen excepcional da Carta Politica de 1937, as atividades legislativas e administrativas se encontravam confundidas na pessoa do Chefe do Govêrno.

8. Cabe, então, indagar: se o ato emanava da mesma autoridade, por que, ao invés de simples decreto executivo, se entendeu baixar ato legislativo, isto é, decreto-lei? Se o Chefe do Govêrno tinha competência constitucional para criar Parques Nacionais por ato administrativo, por que se valeu do disposto no art. 180 da Constituição de 1937 , para baixar decreto-lei sôbre aquela matéria?

9. A primeira vista, essas indagações tem inteira pertinência. Mas a improcedência se torna manifesta, ao simples exame dêsses decreto-leis, quanto à maneira de que tratam, pois que não ficaram tão-sòmente na mera criação daqueles Parques, eis que estabeleceram disposiçôes outras que só seriam admissiveis através de ato legislativo. Donde doncluir-se que a falta de uniformidade é apenas aparente.

10. Com efeito, no que concerne ao primeiro dos decretos-leis citados (Decreto-lei n. ${ }^{\circ} 337$, de 16 de março de 1938), houve autorização para que o govêrno cobrasse taxas de ingresso e de acampamento no Parque, bem como para arrendar os imóveis de serventia pública que nêle construisse (art. $4 .^{\circ}$, caput); para arrendar terras destinadas à construçăo de hotéis, etc., ou permutá-las por outras (art. $5 .{ }^{\circ}$, parágrafo único); dispôs-se, ainda, sôbre a abertura de crédito especial (art. 7. $)$. Ora, tais autorizações constituem matéria de ato legislativo, não podendo constar, por conseguinte, de simples decreto executivo.

11. O mesmo se poderá dizer dos Decretos-leis n. ${ }^{\circ} 1.035$, de 10 de janeiro de 1939 (art. 5..$^{\circ} 1.822$, de 30 de novembro de 1939 (art. 6.\%).

12. Em face do exposto, desde que se năo estabeleçam no decreto executivo disposições čomo as constantes dos decretos-leis citados, mas que se tome por modêlo, verbi gratia, o Decreto n. 45.954, de 30 de abril de 1959 . nada impede que a criação do Parque $\mathrm{Na}$ - 
cional do Araguiaia se faça através de ato do Poder Executivo.

E o meu parecer. S.M.J.

Rio de Janeiro, 11 de novembro de 1959. - Clenicio da Silva Duarte, Consultor Juridico.

\begin{abstract}
Acumulação remunerada. Ainda que decorrente do disposto no art. 24 do Ato das Disposições Constitucionais Transitórias, é restrita a dois cargos públicos. Necessidade de opção.
\end{abstract}

\section{PARECER}

\section{I}

\section{O Dr.. DIOCLECIO}

DANTAS DE ARAúJO recorre de decisão do $\mathrm{Sr}$. DiretorGeral dêste Departamento que, aprovando parecer da Comissão de Acumulaçã̃o de Cargos, intituida pelo Art. 15 do Decreto n. 35.956 , de 2 de agôsto de 1954, considerou ilicito o acúmulo de três cargos públidos, sendo dois de magistério federal superior (cátedras de Anatomia da Faculdade Fluminense de Medicina Cursos de Medicina e Odontologia) e um de Médico da Prefeitura do Distrito Federal, $\mathrm{cm}$ que foi aproveitado na iorma do art. 24

- do Ato das Disposições Constitucionais Transitórias.

2. Pretende o recorrente que a decisão impugnada não tem o beneplácito dos nossos tribunais, conforme procedentes que cita, segundo os quais a ačumulação decorrente do disposto no art. 24 das Disposições Transitórias da Constituição de 1946 não se cinge às normas do art. 185 da nossa Lei Maior.

3. Apreciando o recurso, mantém a comissão especial acima mencionada o seu ponto de vista anterior, solicitando, no entanto, meu parecer sôbre a matéria.

\section{II}

4. As manifestações do Poder Judiciário quanto à insubordinação do art. 24 do Ato das Disposições Constitucionais Transitórias ao art. 185 da Constituição Federal têm apenas o sentido de que a acumulação não se rege pelas condições estatuidas no texto permanente, no que concerne à natureza dos cargos acumuláveis. Não signifičca, entretanto, que, por fôrça do citado dispositivo transitório, se pudesse acumular ilimitado número de cargos públicos.
5. Pelos textos permanentes, a acumulação só é possivel de um cargo de magistério superior ou secundário com outro de juiz (art. 96, n. ${ }^{\circ}$ I), ou de dois cargos de magistério, ou, ainda, de um de magistério com outro técnico ou cientifico, sujeita a acumulação, nos dois últimos casos, à existência de correlação dois últimos casos, à existência de correlação 185).

6. No que concerne à disposição transitória (art. 24), não há exigência quanto à imprescindibilidade de que um dos cargos seja de magistério, podendo ambos serem técnicos ou cientificos, sem que haja mesmo correlação de matérias. Esta a diferença entre os preceitos permanentes e o transitório.

7. Mas é evidente que o número de cargos acumuláveis, seja em decorrênčia do texto permanente, seja em virtude do transitório, está limitado ao número de dois.

8. A norma do art. 24 das Disposições Transitórias de 1946 teve intuito reparatório de direito, com o objetivo de restaurar a situação anterior, sob a égide da Constituição de 1934 . que, de modo semelhante ao texto permanente da Constituição atual, permitia acumulações nas condições expressas no seu art. 172, restritas, todavia, a dois cargos.

9. O recorrente se refere a precedentes judiciários que teriam acolhido a tese que defende. Trata-se de equivoco evidente, pois os casos que menciona não acolhem o cúmulo de três cargos públicos por um mesmo titular. mas o prinčipio de que a acumulação por fôrça do art. 24 das Disposições Constitucionais Transitórias não estaria sujeita à exigência de ser um dos cargos de magistério e que entre êsses cargos haja correlação de matérias. E ponto pacífico essa interpretação, que, em nada, auxilia a pretensão do recorrente.

10. Demais disso, ainda que houvesse manifestação jurisdicional tão esdrúxula, seria caso isolado, que não compeliria a administração a adotá-la, sabido que as decisões jurisdicionais são causuísticas, só obrigando as partes em litígio, pois que a jurisprudência judicial, como tenho acentuado em várias oportunidades e constitui a communis opinio, só se alça à condição de fonte de direito quando iterativa, sem possibilidades de alteração, o que não seria o caso.

11. Em conseqüência, sou pelo não provimento do recurso ora manifestadio, devendo o recorrente exercer o direito de opção, na forma da legislação vigente.

E o meu parecer. S.M.J.

Rio de Janeiro, 9 de dezembro de 1959. - Clenicio da Silva Duarte, Consultor Juridido. 
Conselho Nacional de Pesquisas. Aplicação ao seu pessoal do disposto na Lei n. ${ }^{\circ} 3.483$, de 1958. Revogação tácita do art. 24, alinea c, da Lei n." 1310, de 1951.

\section{PARECER}

Indaga a D.P. dêste Departamento sôbre a aplicação, ao pessoal do Conselho Nacional de Pesquisas, do disposto na Lei n. ${ }^{\circ} 8.483$, de 8 de dezembro de 1958 , tendo em vista o parecer do então Dr. Consultor-Geral da República, em caso semelhante de interêsse do Ins. tituto Brasileiro de Geografia e Estatistica (parecer de referência $557-Z$, de 23 de julho de 1959, publicado no Diário Oficial de 25 de agôsto daquele ano, à pág. 18.422).

2. O pessoal do Conselho Nacional de Pesquisas a que se refere a consulta foi admitido na conformidade do art. 24, alinea c, da Lei n. ${ }^{\circ} 1.310$, de 15 de janeiro de 1951, que criou aquela autarquia, cuja redação é a seguinte:

«c) o Conselho poderá admitir pessoal não caracterizado como permanente ou extranumerário, para melhor consecução de suas finalidades».

3. $\mathrm{O}$ art. $10^{\circ}$ (caput) da Lei $\mathrm{n}^{\circ}$ 3.483, de 8 de dezembro de 1958, cuja incidência se discute, está por esta forma redigido:

«Os empregados admitidos à conta de dotações constantes das verbas 1.0 .00 Custeio, Consignação 1.6.00 - Encargos Diversos, 3.0.00 - Desenvolvimento Econômico e Social, Consignação 8.1 .00 Serviços em Regime Especial de Financiamento, e 4.0.00 - Investimentos, Consignação 4.1.00 - Obras, ficam equiparados aos extranumerários mensalistas da União desde que contem ou venham a contar 5 (cinčo) anos de exercício».

\section{II}

4. A simples caracterização do pessoal de que se trata como não permanente, na forma do art. 24 , alinea $\mathrm{c}$, da Lei n. ${ }^{\circ} 1.310$, de 1951, cuja transcrição se fêz acima, parece aconselhar a sua não inclusão entre os amparados pelo art. $10^{\circ}$ (caput) da Lei n. ${ }^{\circ} 3.483$, de 1958, por isso que passaria, com essa incidência, a permanente, com a equiparação de que ali se cogita.

5. Tal fato, entretanto, não deve impressionar, pois a natureza da função de todos os que a lei ampara era de suma precaridade, como se verifica pelas verbas e consignações por que se efetuavam os respectivos pagamentos. Logo, a mens legis é outra, não interferindo na interpretação a circunstância da natureza não permanente das funções exercidas.

6. E certo que a lei faz menção expressa às verbas e consignaçốes por que ocorre o pagamento com o pessoal amparado, restringindo, em consequiência, a sua aplicação. Mas êsse fato também não é óbice para a incidência ao pessoal do Conselho Nacional de Pesquisas dos benefícios do art. $10^{\circ}$ da Lei número 3.483 , de 1958 , como se verá.

7. Com efeito, sôbre êsse aspecto, assim opinei em outra oportunidade (parecer emitido no processo n. ${ }^{\circ} 7.720-59$, publicado no Diário Oficial de 27 de julho de 1959 , às págs. 14.785 e 14.786):

«A lei não visou sòmente aos admitidos à conta de dotaçōes constantes das verbas enumeradas no seu art. $1 . \%$ pois que se ali se fala nos que venham a contar 5 anos de exercício, também se mencionam os que já contem êsse número de anos. E nenhum empregado admitido à conta das dotações daquelas verbas poderia contar 5 anos de exercicio, eis que a reclassificação de esquema da despesa pública léderal data apenas de 1956.

A enumeração das verbas constantes do art. $10^{\circ}$ da Lei n. ${ }^{\circ} 3.483$, de 1958 , não esgota os recursos para custeio da admissão do pessoal por ela beneficiado, cabendo ao intérprete perquirir da natureza da respectiva relação de emprêgo».

8. Acrescente-se, no caso, que, sendo o órgão, a que pertence êsse pessoal, autarquia, «não há nos orçamentos dessas entidades» como também salientei em outro parečer processo $\left.\mathrm{n}{ }^{\circ} 10.733-59\right)$ - «a obrigatoriedade de classificação do sistema de despesa nos moldes do orçamento da União».

9. Parece-me, em face do exposto, que se aplica ao pessoal do Conselho Nacional de Pesquisas - o que é o objeto propriamente de consulta - a orientação preconizada pelo então ilustre Consultor-Geral da República no parecer acima referido, quando opinou sôbre hipótese semelhante, relativamente a empregados do Instituto Brasileiro de Geografia e Estatistica.

10. A incidência do art. $10^{\circ}$ (caput) da Lei n..$^{\circ} 3.483$, de 1958 , ao pessoal do Conselho Načional de Pesquisas, importa, por via de consequiência, na revogação do art. 24 , alinea $\mathrm{c}$, da Lei $\mathrm{n} \cdot 1.310$, de 1951 , sujeitando a admissão futura de pessoal às demais normas da mencionada Lei n. ${ }^{\circ} 3.488$, de 1958. 
11. Tratando-se, na espécie, do pessoal equiparado, não há como cogitar de organização de tabela de extranumerário mensalista, como pretende o Conselho, pois não ocorreu transformação, mas simples equiparação, o que se acha claramente especificado no art. $10^{\circ}$ da Lei n. ${ }^{\circ} 3.483$, de 1958.

É o meu parecer. S.M.J.

Rio de Janeiro, 18 de abril de 1960. - Clenicio da Silva Duarte, Consultor Jurídico.

Servidor público condenado a pena privativa de liberdade superior a dois anos, como incurso no art. 229, § 1.* do Código Penal Militar (peculato doloso). Imposição automática da pena acessóría da perda da função pública, nos têrmos do art. 53, n." II, do mesmo Código.

\section{PARECER}

1

Extranumerário mensalista do Ministério da Marinha foi condenado a 3 anos e 3 meses de reclusão, como incurso no art. 229, § 1. , do Código Penal Militar.

2. A sentença condenatória não declarou a perda da função pública, não obstante o disposto no art. $55, \mathrm{n}^{\circ} \mathrm{I}$, do mesmo Código, que o Ministério da Marinha entendeu ser aplicável à espécie, com o que concorda a $\mathrm{Di}$ visão de Pessoal dêste Departamento.

3. Discute-se, então, se a omissão da sentença tem por efeito, na hipótese, a não perda da função pública de que é titular o condenado.

\section{II}

4. O art. $55, \mathrm{n} \cdot{ }^{\circ}$ 1, do Código Penal Militar estabelece:

\section{Art. 55. A sentença deve declarar:}

I - a perda da função pública, nos casos do n. ${ }^{\circ} 1$ do art. 53».

5. O art. 53 do citado Código estatui: «Art. 53. Incorre na perda da função pública o assemelhado ou civil:

I - condenado à pena privativa de liberdade por crime cometido com abuso de poder ou violação de dever inerente à função pública:

II - condenado por outro crime à pena privativa da liberdade por mais de dois anos».

6. Tem-se, em conseqüência, que o crime cometido por assemelhado ou civil, titular de função pública, quando importa em abuso de poder ou violação de dever inerente à função pública (art. 53, n. ${ }^{\circ} \mathrm{I}$ ), determina, qualquer que seja a pena imposta, a perda daquela função, devendo a sentença declará-la expressamente, nos têrmos do art. $55, \mathrm{n} .^{\circ} \mathrm{I}$, do Código Penal Militar. No caso do $n .^{\circ}$ II do art. 53 dessa codificação, a perda da função pública é automática, independendo, por êsse efeito, de declaração constante da sentença condenatória.

7. A necessidade da expressa declaração, na hipótese de condenação por crime funcional a que se cominou pena igual ou inferior a dois anos, provém de que, com essa declaração, se conceitua o abuso de poder ou a violação de dever inerente à função pública. Do contrário, não há como fugir à censura de Sílvio Martins Teixeira (Novo Código Penal Militar do Brasil, Freitas Bastos, 1946, pág. 139), que pondera ser «escusada a declaração na sentença, porque o efeito segue à causa, é seu resultado inevitável».

8. No caso do processo, o crime cometido foi o capitulado no art. 229 , $₹ 1 .^{\circ}$, do Código Penal Militar (peculato doloso), correspondente ao art. $312, \S 1 .^{\circ}$, do Código Penal comum, cuja pena, em grau mínimo, é de 3 anos de reclusão.

9. A espécie, por conseguinte, está prevista no art. 52 , n. ${ }^{\circ}$ II, do Código Penal Militar, pois que se trata de condenação a pena privativa de liberdade por mais de dois anos, quando a perda da função pública é conseqüência automática da sanção aplicada.

10. Os casos do n. ${ }^{\circ}$ I do art. 53 se destinam a crimes cometidos com abuso de poder ou violação de dever inerente à função pubblica, mesmo que a condenação seja a pena inferior, devendo, na forma do art. $55, \mathrm{n} .^{\circ} \mathrm{I}$, ser declarada expressamente na sentença.

11. A inexistência da declaração expressa, na hipótese do processo, deflui de que não se entendeu que o crime fôra praticado com abuso de poder ou violação de dever inerente à função pública. E a condenação a pena privativa da liberdade superior a dois anos, já importava, automàticamente, na perda da função, nos têrmos do art. $53, n .^{\circ}$ II. 
II. De fato, o peculato não se caracteriza pelo abuso do poder ou pela violação do dever inerente à função pública. $\mathrm{O}$ dever juridico violado é de ordem geral, não intrinseco à função pública, embora o sujeito ativo seja funcionário público. Vale dizer, o peculato, para ser cometido, não importa, necessàriamente. por parte do agente, em abuso do poder ou violação de dever inerente à função pública. Há violação de dever jurídico de ordem genérica, não caracteristicamente funcional.

13. De qualquer modo, porém, só se poderia discutir, em face da omissão da sentença, a não perda da função pública pelo agente se a condenação à pena privativa de liberdade fôsse igual ou inferior a dois anos. Sendo superior, cai a hipótese no $\mathrm{n} .^{\circ}$ II do artigo 53, quando a imposição da pena acessória é automática, já que o abuso de poder ou a violação de dever inerente à função pública são circunstâncias que só poderiam agravar e nunca atenuar a punibilidade.

14. Entende, pois, que a condenação imposta ao servidor ( 3 anos e 3 meses de reclusão), como incurso no art. $229, \S 1 .^{\circ}$, do Código Penal Militar (peculato doloso), acarreta-lhe, automàticamente, a perda da função pública, nos têrmos do art. $53, \mathrm{n} .^{\circ}$ II, da mesma codificação.

E o meu parecer. S.M.J.

Rio de Janeiro, 3 de maio de 1960. Clenicio da Silva Duarte, Consultor Juridico.

Isenção de impostos e taxas aduaneiras sôbre materiais e equipamentos importados pelo Ponto $I V$. Idem, sôbre as mercadorlas de uso pessoal ou doméstico, trazidas ao pais para uso próprio e de suas familias, pelos funcionários do govêrno americano, a que se referem acôrdos celebraldos entre o Brasil e os Estados Unidos da América.

\section{PARECER}

\section{I}

O Sr. Diretor-Geral dêste Departamento determinou o pronunciamento desta Consultoria Juridica sôbre expediente elabroado pelo Sr. Diretor-Executivo do Escritório Técnico da Representação Brasileira do Ponto IV, relativo à isenção de direitos alfandegários e taxas aduaneiras, nos têrmos do Acôrdo Básico de Cooperação Técnica e do Acôrdo sôbre Programas de Serviços Técnicos Especiais, concluidos entre o Brasil e os Estados Unidos da América, assinados no Rio de Janeiro a 19 de dezembro de 1950 e 30 de maio de 1953 , respectivamente, os quais foram aprovados pelo Congresso Nacional, através do Decreto Legislativo n. ${ }^{\circ} 16$, de 1959.

2. Esclarece-se no processo que, não obstante as isenções previstas naqueles acôrdos, as autoridades alfandegárias e portuárias brasileiras, após a vigência das Leis ns. 3.381, de 24 de abril de 1958, e 3.421 , de 10 de jutho do mesmo ano, passaram a exigir o pagamento, pelo Ponto IV, das Taxas de Renovação da Marinha Mercante (5\% sôbre os fretes maritimos) e de Melhoramentos dos Portos ( $1 \%$ sôbre o valor comercial das merdadorias importadas).

3. Como não houvesse ainda o Congres. so Nacional aprovado aquêles acôrdos, o que só ocorreu com o Decreto Legislativo n ${ }^{\circ} 16$, de 1959, publicado no Diário Oficial de 13 de novembro do ano próximo passado, baixou o Poder Executivo o Decreto n. ${ }^{\circ} 44.609$, de 8 de outubro de 1958, isentando, temporàriamente, das referidas taxas as mercadorias ali especificadas, nos têrmos do seu art. $1 .^{\circ}$, assim redigido:

«Art. 1. ${ }^{\circ}$ As mercadorias e equipamentos importados nos têrmos do Acôrdo Básico de Cooperação Técnica e do Acôrdo sôbre Programas de Serviços Técnicos Especiais, concluidos entre o Brasil e os Estados Unidos da América representados pelo «Instituti of Interamerican Affairs «International Corporation Administration Ponto IV), bem como a bagagem de técnicos da Administração dos referidos acôrdos que se destinarem ao Brasil, f cam isentos temporàriamente do pagamento de quaisquer taxas, especialmente as a que se referem as Leis números 3.421 , de 10 de julho de 1958 , e 3.381 , de 24 de abril de 1958 , mediante assinatura de têrmos de responsabilidade, até ulterior deliberação do Congresso Nacional» .

4. Indaga-se, agora, se, com a aprovação pelo Congresso Nacional dos acôrdos interna- 
cionais citados, foi ratificada a isenção, inclusive tornando-se desnecessário o têrmo de responsabilidade a que se refere o mencionado Decreto $n .^{\circ} 44.609$, de 1958 , ou se dita aprovação não tem êsse efeito.

\section{II}

5. O Acôrdo Básico de Cooperação Técnica e o Acôrdo sôbre Programas de Serviços Técnicos Especiais, concluidos entre o Brasil e os Estados Unidos da América, após a sua aprovação pelo Congresso Nacional, através do Decreto Legislativo n. ${ }^{\circ} 16$, de 1959 , incorporaram-se à legislação nacional, pois que, para tanto, só dependiam dessa formalidade.

6. A cláusula décima do Acôrdo Básico dispõe:

«10. Quaisquer fundos, materiais e equipamentos fornecidos ao Brasil pelo Govêrno dos Estados Unidos da América, como resultado dos ajustes sôbre projetos e programas de cooperação técnica, serão isentos de impostos, taxas e exigências relativas a depósitos e investimentos. Todos os funcionários do Govêrno dos Estados Unidos da América designados para servir no Brasil em conexão com os programas de cooperação técnica, assim como os membros das respectivas familias, estarão isentos dos impostos bras leiros sôbre a renda, taxa de previdência social e impôsto sôbre a propriedade pessoal, assim como de direitos de importação, em condiçöes iguais às outorgadas às outras missões ou comissões não-diplomát cas dos Estados Unidos da América no Brasil».

7. O artigo IV - Direitos e Isenções do Acôrdo sôbre Programas de Serviços Técnicos Especiais, por sua vez, estatui:

«1. O Govêrno dos Estados Unidos do Brasil concorda em conceder a cada projeto empreendido nos têrmos dêste Acôrdo, bem como a todo o pessoal que trabalha nesses projetos, todos os direi- tos e privilégios conferidos, pelas suas leis, a seus órgãos e respectivo pessoal.

2. Os equipamentos e materiais, inclusive os de consumo, fornecidos pelo Govêrno dos Estados Unidos da América, quer diretamente, quer mediante contrato com organização pública ou privada, para a execução de qualquer projeto empreendido nos têrmos dêste Acôrdo, entrarão nos Estados Unidos do Brasil livres de quaisquer direitos alfandegários e de importação.

3. Os direitos e privilégios a que se refere o parágrafo $1 .^{*}$ dêste $\mathrm{Ar}$ tigo também serão concedidos à Administração e ao pessoal do Govêrno dos Estados Unidos da América, no que se refere às atividades relacionadas com a execução de qualquer projeto empreendido nos têrmos dêste Acôrdo e aos bens materiais para tal fim utilizados.

4. Todo o pessoal do Govêrno dos Estados Unidos da América, empregado diretamente, ou mediante contrato com organização pública ou privada, que se encontre nos Estados Unidos do Brasil para executar trabalho decorrente do presente Acôrdo, e cuja entrada neste último país tenha sido aprovada pelo respectivo Govêrno, nos trmos do Art go 1." do presente Acôrdo, gozará: relativamente a rendimentos sôbre os quais deva pagar impôsto de renda e taxas de previdência social ao Govêrno dos Estados Unidos da América, da isenção de impôsto de renda e taxas de previdência social, estabelecidas nas leis brasileiras; de isenção de taxas sôbre bens materiais destinados a uso próprio; e de isenção de pagamento de qua squer impostos e direitos alfandegários 
sôbre mercadorias de uso pessoal ou doméstico, trazidas ao país para uso próprio e de suas familias. A intervalos conven entes, o Embaixador dos Estados Únidos da América junto ao Govêrno dos Estados Unidos do Brasil fornecerá ao Ministro das Relações Exteriores dêste uma relação do pessoal a que deverão ser aplicadas as disposições do presente parágrafo».

8. Da-redação dos textos transcritos nos itens 6 e 7 dêste parecer, verifica-se que a isenção tributária incide de modo total, no que concerne aos materiais e equipamentos importados para a execução de qualquer projeto empreendido nos têrmos daqueles acôrdos. Alcança não só os direitos de importação e impostos alfandegários como as taxas aduaneiras, entendidas estas no seu conceito técnico, isto é, contribuição arrecadada em troca de prestaçăo de serviços fornecida pela administração, ou de despesas especiais necessárias à realização dêsses serviços (Cf. Bilac Pinto, Estudos de Direito Público, pág. 153).

9. Assim, quanto a êsses materiais e equipamentos, não há interêsse prático, dada a amplitude da isenção conferida, - que abrange \&impostos, taxas e exigências relativas a depósitos e investimentos» (cláusula décima do Acôrdo Básico, - sôbre a conceituação das Taxas de Renovação da Marinha Mercante, criada pela Lei n. ${ }^{\circ} 3.381$, de 1958 (art. 8..$^{\circ}$ ), e de Melhoramento dos Portos, instituida pela Lei n. ${ }^{\circ} 3.421$, também de 1958 (art. $3 .^{\circ}$ ). Não há, pois, que examinar, na espécie, se a denominação de taxas dada a êsses tributos corresponde ao conceito técnico da contribuição.

10. Quanto aos funcionários do Govêrno dos Estados Unidos da América, a que se referem a cláusula décima do Acôrdo Básico e o Art. IV do Acôrdo sôbre Programas de Serviços Técnicos Especiais, já o mesmo não ocorre, pois a isenção conferida só alcança direitos e impostos de importação e a taxa de previdência social, que, como esclareci em outra oportunidade (parecer emitido no processo número 9.358-56), é verdadeiro impôsto.

11. A isenção, no que respeita a êsses funcionários, não atinge as taxas pròpriamente ditas, pois, do contrário, ter-se-ia de especificar claramente, visto que, como é pacifico, correspondendo a taxa à contraprestaçăo por um serviço efetivamente prestado, nã́o se compreende no conceito de impôsto ou de direitos alfandegários.
12. Impõe-se, em conseqüência, perquirir da natureza das chamadas Taxas de Renovação da Marinha Mercante e de Melhoramento dos Portos.

13. A Taxa de Renovação da Marinha Mercante, criada pela Lei n. ${ }^{\circ} 3.381$, de 24 de abril de 1958 (art. $8 .^{\circ}$ ) em substituiçăo à instituida pelo Decreto-lei n. ${ }^{\circ} 3.100$, de 7 de março de 1941 , alterado pelo de n. ${ }^{\circ} 3.595$, de 5 de setembro de 1941, tem característica do impôsto pròpriamente dito, eis que não satisfaz nenhum dos elementos essenciais da taxa, segundo o excelente resumo de Bilac Pinto (ep. cit., págs. 158 e 159). São êles: «1. ${ }^{\circ}$ ) O primeiro elemento essencial da taxa moderna é que uma soma de dinheiro é entregue por um individuo ao Estado na ocasião de um serviço determinado prestado a êsse individuo, de uma vantagem especial obtida de agentes públicos. $O$ individuo paga, porém recebe vantagem determinada: há prestação e contraprestação. E por isso que se diz às vêzes que as taxas são impostos especiais. $2 .^{\circ}$ ) As taxas

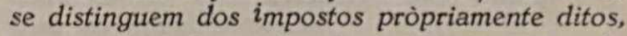
porque o impôsto não é contraprestação de uma prestação, definida, de uma vantagem especial para o individuo que a paga: é uma soma paga em razão do fato de que o individuo se prende ao Estado por certo, vinculo, ,nacionalidade, domicilio, residência, etc.)». Também assim se manifesta Aliomar BALEEIro (Ulma Introdução à Ciência das Finanças, volume I, pág. 311): «O benefício especial objetivo, mensurável, é condição essencial para que o tributo seja conceituado como taxa».

14. Ora a soi-disant «Taxa» de Renovação da Marinha Mercante não corresponde a qualquer serviço prestado, de que seja ela a contraprestação. Logo, está abrangida no conceito de impostos de importação, de que se acham isentos aquêles funcionários.

15. O mesmo ocorre com a Taxa de $\mathrm{Me-}$ lhoramento dos Portos, criada pela Lei número 9.421 , de 10 de julho de 1958 , em substituição à Taxa de Emergência instituida pelo Decreto-lei $\mathrm{n} .^{\circ} 8.311$, de 6 de dezembro de 1945, da qual, também, ao meu parecer, pelos mesmos motivos, estão isentos os funcionários de que se trata.

16. Em conclusão:

a) os materiais e equipamentos importados para a execução de qualquer projeto empreendido nos têrmos dos dois Acôrdos a que se referem o processo estão isentos de quaisquer tributações de importação, quer se conceituem como impostos pròpriamente ditos e direitos alfandegários, quer se revistam das caracteristicas de taxa, entendida esta no con- 
ceito técnico que lhe emprestam a doutrina e a jurisprudência:

b) os funcionários mencionados naqueles Acôrdos se acham isentos dos direitos e impostos de importação, compreendidos entre êstes a taxa de previdência social e as referidas nas Leis ns. 8.381, de 24 de abril de 1958 , e 3.421 , de 10 de julho do mesmo ano, não alcançando a isenção taxas pròpriamente ditas, porventura já incidentes ou que venham a incidir sôbre aquelas importações:

c) quanto ao Têrmo de Responsabilidade de que cogita o Decreto n. ${ }^{\circ} 44.609$, de 8 de outubro de 1958, não há mais necessidade de sua assinatura, porquanto já se acham aprovados pelo Congresso Nacional os Acôrdos ali referidos.

E o meu parecer. S.M.J.

Rio de Janeiro, 11 de maio de 1960. Clenicio da Silva Duarte, Consultor Juridico.

\section{Aplicação da Lei n. ${ }^{\circ} 1.741$, de 1952, a servidores autárquicos. Incidência, à espécie, do disposto no art. $6 .^{\circ}$ do Decreto n. ${ }^{\circ} 40.746$, de 1957.}

\section{PARECER}

\section{I}

Funcionário autárquico, ocupante de cargo da classe L da carreira de Oficial Administrativo da Caixa de Aposentadoria e Pensões dos Ferroviários e Empregados em Serviços Públicos (C.A.P.F.E.S.P.), pretende o beneficio do art $10^{\circ}$ da Lei n.o 1.741 , de 22 de novembro de 1952, sob a alegação de que exerceu, durante mais de dez anos consecutivos (de 13-9-1944 a 22-11-1954, o cargo, em comissão, de Chefe da Carteira de Empréstimos da extinta Caixa de Aposentadoria e Pensões dos Serviços Aéreos e Tele-comunicações, sendo o seu, afastamento dêsse cargo oriundo da extinção do mesmo.

2. A D. P. dêste Departamento opina contràriamente ao pedido, por entender que, no caso, a situação do funcionário não preenche os requisitos dos arts. $3 .^{\circ}$ e $6.0^{\circ}$ do Decreto n. ${ }^{\circ} 40.746$, de 15 de janeiro de 1957 , que regulamentou a citada Lei n. ${ }^{\circ} 1.741$, de 1952, já que a transformação do cargo em comissão não ocorreu com a ressalva da situação pessoal do suplicante e a legislação especifica da autarquia (C.A.P.F.E.S.P.) não prevê o benefício para o seu pessoal. Nada obstante, deseja aquela Divisão meu parecer sôbre a matéria, que teve solução diversa em decisão jurisdicional anexa ao processo por cópia.

\section{II}

3. A aplicação da vantagem conferida pela Lei n. ${ }^{\circ} 1.741$, de 1952 , aos servidores autárquicos só pode derivar de determinação legal ou regulamentar nesse sentido, uma vez que êsse diploma legal não atingiu diretamente a administração descentralizada. Trata-se de benefício excepcional, derrogatório, em certo sentido, do sistema estatutário vigente, que considera precária a investidura em cargo em comissão, sujeita a demissão ad nutum. Sôbre êsse aspecto infringente das normas gerais, assim me manifestei em parecer emitido no processo n. ${ }^{\circ} 13 \cdot 141-54$, publicado no Diário Oficial de 2 de abril de 1956, à pág. 6.147; Revista do Serviço Público, abril de 1956, págs. 165 a 167 , e Revista de Direito Administrativo, vol. 45 , págs. 416 a 419 :

$\ll \mathrm{O}$ art. $1 .^{\circ}$ da Lei n. ${ }^{\circ} 1.741$, de 1952 , é uma norma de exceção. Foge a tôda a sistemática da legislação do pessoal, para assegurar um benefício que não encontra fundamento lógico, divorciado que se acha do próprio conceito de cargo em comissão, inconciliável com o de estabilidade. Embora não assegure esta, o que seria verdadeira revolução no sistema vigente, garante os respectivos vencimentos, quando o ocupante é exonerado do cargo, satisfeitos os requisitos que estabelece».

4. Se é certo que a lei só assegurou a vantagem aos funcionários da administração direta, a previsão do mesmo beneficio para os servidores autárquicos pode ocorrer, ou por fôrça de preceituação legal especifica, ou em virtude de decreto executivo, cabivel êste último, na espécie, por se tratar de administração indireta, quando a competência do Poder Executivo se pode fazer sentir com maior amplitude.

5. De qualquer modo, porém, é imprescindivel à previsão legal ou regulamentar do beneficio, por isso que o Legislativo não cuidou de cargos autárquicos. Nesse sentido, é clara a disposição do art. $6 .^{\circ}$ do Decreto n. ${ }^{\circ} 40.746$, de 1957 , cuja redação é a seguinte:

«Observadas as disposições dêste decreto, as vantagens a que se refere a Lei n. $0^{\circ} 1.741$, de 22 de novembro de 1952 , serão extensivas aos ocupantes de cargos em comissão de autarquia desde que sejam previstas na legislação especifica de cada entidade» (grifei). 
6. No caso, esclarecerse que não há previsão na C.A.P.F.E.S.P. quanto à concessão da vantagem aos seus servidores. Em conseqüência, não há como deferi-la.

\section{III}

7. A decisão jurisdicional invocada, de que se juntou cópia neste processo, entende que a norma do art. $1 .^{\circ}$ da Lei n. ${ }^{\circ} 1.741$, de 1952, é de si aplicável aos servidores autárquicos, sem maiores formalidades, talvez arrimando-se no preceituado no art. 252 , n. ${ }^{\circ}$ II, do Estatutō dos Funcionários, que considera extensivel aos servidores autárquicos, no que couber, o regime jurídico daquele código.

8. Não me parece, data venia, acertada a conclusão, pois, como esclarecemos no item 3, não se trata de vantagem estatutária, mas de disposição, de certo modo, derrogatória do sistema daquele Estatuto.

9. Quanto ao que se contém no art. $3 .^{\circ}$, in fine, do Decreto n. ${ }^{\circ} 40.746$, de 1957, isto è, à exigência de que a transformação do cargo em comissão em função gratificada se tenha feito com ressalva da situação pessoal do respectivo ocupante, não atingiria a hipótese do processo, pois que, se aplicável a vantagem, esta o seria antes daquela transformação, visto que, à época, já contava - requerente mais de dez anos de serviço ininterruptos no cargo em comissão transformado. E aspecto, entretanto, meramente de interêsse doutrinário, eis que não incide sôbre a espécie o art. $10^{\circ}$ da Lei n. 1.741 , de 1952 , como já esclareci, dado que a C.A.P.F.E.S.P. não possui legislação que assegure o beneficio, na forma do preceituado no art. $60^{\circ}$ do referido Decreto n. ${ }^{\circ} 40.746$, de 1957.

10. Sendo a decisão jurisdicional casuistica, como inúmeras vêzes tenho salientado, constituindo, aliás, matéria pacifica, não está a administração adstrita a tomá-la como norma para aplicação a casos ainda que semelhantes, mormente tendo em conta que - Supremo Tribunal Federal não chegou a opinar sôbre o mérito, não conhecendo do recurso extraordinário manifestado por importar a hipótese em decisão interpretativa de texto de lei, com o que se não configurava caso do apêlo incomum.

11. Em face do exposto, sou também pelo indeferimento do pedido.

É o meu parecer. S. M. J.

Rio de Janeiro, 28 de março de 1960. Clenício Da Silva Duarte, Consultor Juridico. 